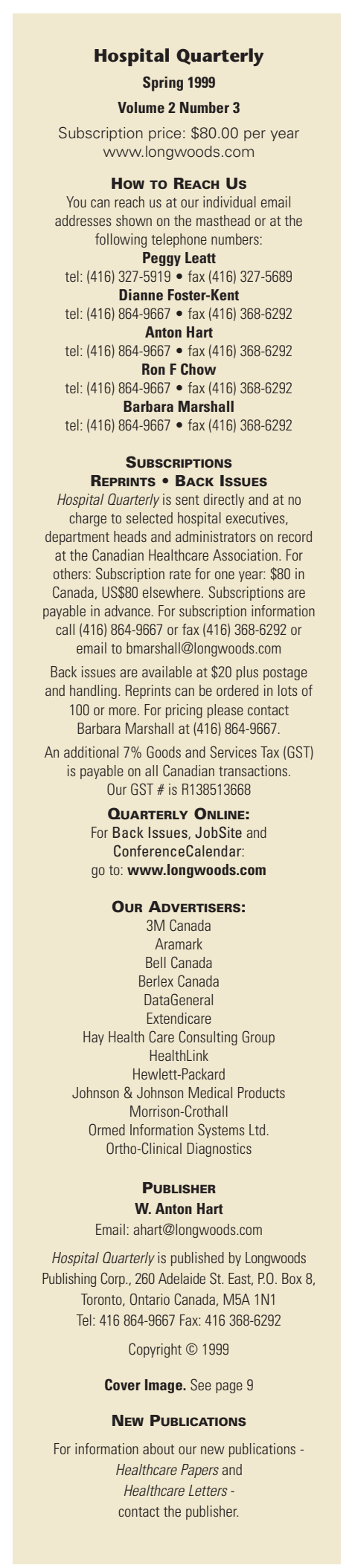

\title{
What Do Canadians Think of the Healthcare System?
}

The marks are in for scoring the Canadian healthcare system and the quality of services it provides. According to Hoechst Marion Roussel's second annual Canadian Consumer Survey on Healthcare, Canadian group benefit plan members give these high marks to their publicly funded healthcare system: $78 \%$ rate Medicare as "good" or "very good." Compared with last year, however, slightly fewer are calling it "excellent" and marginally more are rating it "very poor." Only $7 \%$ overall judged it "excellent" this year, a slight drop from last year's $9 \%$. Last year's survey results showed that $66 \%$ of Canadians deemed healthcare "good" or "very good."

The proportion rating it "poor" or "very poor" amounts this year to $14 \%$, more than double the percentage of $6 \%$ recorded in last year's Hoechst Marion Roussel survey.

By region, Quebecers are once again less enthusiastic about the state of healthcare: a scant $4 \%$ rate it "excellent" in this year's survey. Last year's poll found Quebec residents, who began to experience healthcare restructuring a good ten years before other provinces, were most apt to give healthcare a dismissive "fair" grade.

In the current poll, Ontarians and British Columbians are the likeliest to give high marks to Medicare: $10 \%$ and $9 \%$, respectively, say it is "excellent." But the enthusiasm of BC plan members seems to have faded somewhat since last year when 13\% accorded Medicare an "excellent." The dimmest view is taken in Saskatchewan and Manitoba, where $23 \%$ of respondents rank healthcare as "poor" or "very poor." Clearly, health-resource cuts and frequent hospital closings in these two prairie provinces are not lost on their residents.

Interestingly, those who report poorer health and perhaps having more exposure to the Canadian healthcare system, are less likely to give Medicare top marks: only $3 \%$ of respondents reporting their own health as "fair" or "poor" rate Medicare as "excellent," while $11 \%$ in "excellent" health do so. Those 55 years of age and older are more likely to give Medicare a failing grade: $21 \%$ rate it as "poor"/"very poor." Compare that figure with the $10 \%$ of consumers aged 18 to 34 and the $14 \%$ aged 35 to 54 who give Medicare the lowest marks.

Similarly, respondents filling more than four prescriptions per year, and more personally familiar with medical services, are the most likely to rate the system as "poor"/"very poor:" 19\% of those reporting more than four prescriptions a year versus $11 \%$ of those filling none or one prescription. And in an echo of last year's survey,
Canadians' attitudes towards the healthcare system and the quality of services it provides

\section{Excellent/Very good}
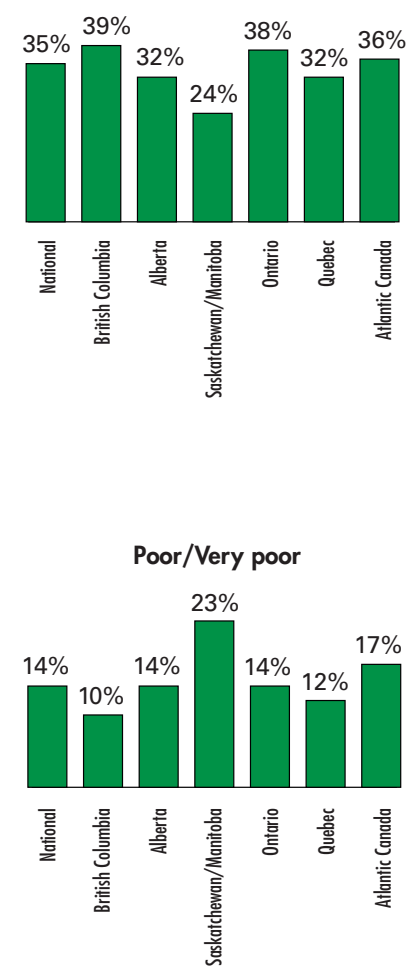
Rating healthcare "poor" or "very poor:" the influence of age, health condition and annual number of personal prescriptions on levels of dissatisfaction

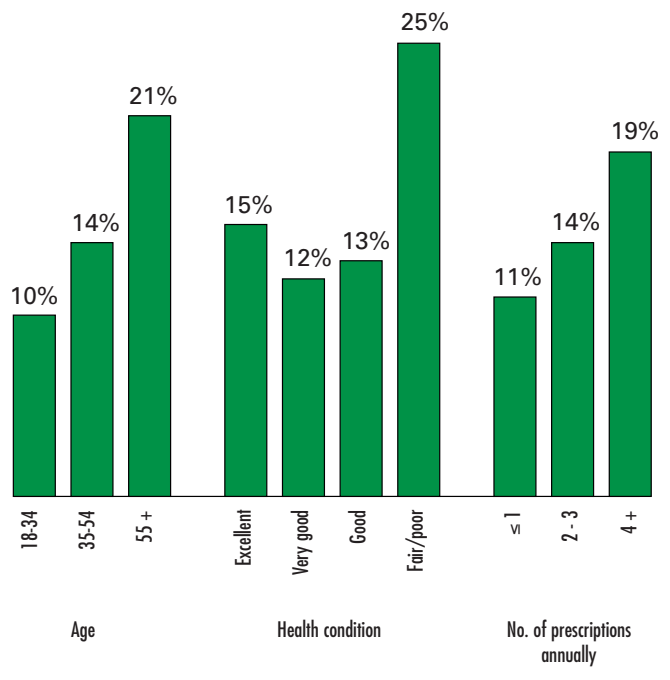

Rating healthcare "excellent" or "very good:" the correlation between education, personal income and satisfaction with the current system

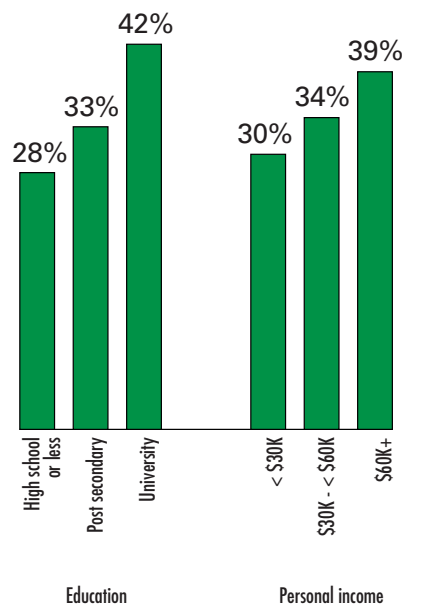

women, who access the healthcare resources for themselves or their children more often than men, are slightly more inclined to relegate Medicare quality to the bottom two categories: $16 \%$ versus $12 \%$ of men.

Income, job and educational status also appear to have an impact on attitudes towards Medicare. Those with some university training are the most apt to declare the system "excellent" or "very good:" $42 \%$ compared with $28 \%$ of those with high school or less. And nearly four-in-ten Canadians whose personal income exceeds $\$ 60,000$ rank it in the top two categories, compared with three-in-ten of those whose incomes are less than $\$ 30,000$. And as with both Hoechst Marion Roussel polls, a June 1998 Angus Reid survey also found woman were less satisfied with Medicare than men: $80 \%$ versus $65 \%$ identified a deterioration in Canada's health services system. By age, the most inclined to say Medicare had worsened were those 35 to 54 years old - this in contrast to other polls that point to the over-55s as the least satisfied.

So, while Canadians continue to have confidence in publicly funded Medicare, that confidences seems to be slowly eroding.

Although this year's survey finds no clear consensus on how Medicare should be financially supported, it picks up indications that Canadians are increasingly ready for a change. While $41 \%$ opt for the existing totally tax-funded system, 57\% endorse a mixed approach, in which funding is shared by patients through co-payments and user fees.

Compared with last year's results, these figures represent a slight progression toward support for accepting more personal responsibility for the financial health of Medicare: in 1998, 44\% favoured maintenance of a totally public system, while $54 \%$ endorsed co-payments from users.

Geographically, the highest support (66\%) for a revamped funding arrangement is seen once again in Quebec, where dissatisfaction with existing Medicare runs quite deep. Following Quebec in approval of a change is B.C. at 63\%, while the least support for a mixed funding system comes once again from the Atlantic provinces (41\%).

When we examine health status, exactly half of those reporting their own health as "fair" or "poor" give the highest approval for a healthcare system funded entirely from the tax base. This is markedly different than the 38\% of those reporting "excellent" health supporting this type of funding. Similarly, $46 \%$ of those filling more than four prescriptions a year endorse a public system, versus 38\% of those using no prescriptions. IQQ

The Angus Reid Group conducted The Canadian Consumer Survey on Healthcare through telephone interviews across Canada with a random sample of 1,508 primary group insurance plan members who had a medical benefits portion to their plan. Interviews were completed between November 25th and December 10th, 1998. With a national sample of 1,508 interviews, one can say with $95 \%$ certainty that the results of the survey are within $+/-2.5$ percentage points of what they would have been had the entire population of group insurance plan members been polled. However, it must be noted that the margin of error is larger among subsample groupings respondents. 